Agr. Biol. Chem., 38 (6), 1195 1202, 1974

\title{
Isolation and Characterization of Acidic Peptides in Soy Sauce
}

\author{
Satoru OKA and Kazuya NAGATA* \\ Department of Fermentation Technology, Faculty of Engineering, \\ Hiroshima University, Hiroshima 730
}

Received December 24, 1973

\begin{abstract}
A soy sauce sample was fractionated by gel filtration on a Sephadex G-15 column, then the fractions were subfractionated on the basis of acidity by ion exchange chromatography on a QAE-Sephadex A-25 column. The acidic subfractions with various acidities were further fractionated, using a preparative amino acid analyzer and by paper chromatography to separate the acidic peptide components.

Four dipeptides and sugar derivatives of ten dipeptides and two tripeptides were isolated and characterized as the major acidic peptides in soy sauce. However, it was difficult to anticipate any direct contribution of these peptides to the flavor construction in soy sauce on the basis of their contents and taste intensities.
\end{abstract}

In the preceding work, "' a soy sauce sample was fractionated by gel filtration on a Sephadex G-15 column, then the fractions were subfractionated on the basis of acidity by ion exchange chromatography on a QAE-Sephadex A-25 column. After the preliminary fractionation, the components in the neutral subfractions were converted to copper salts and chromatographed on a DEAE-Sephadex column to separate peptide substances from a large amount of free amino acids. The peptide fractions were further fractionated on a preparative amino acid analyzer and by paper chromatography to separate the peptide substances. Thus, three glycodipeptides and eight dipeptides were isolated and characterized as the major neutral peptide components in soy sauce. However, the practical contributions of these components to the flavor construction in soy sauce were evaluated as negligibly small.

The present work deals with the peptide substances in the acidic subfractions obtained by the preliminary fractionation. Major acidic peptide components were isolated from the acidic subfractions and characterized, and their

$\uparrow$ Studies on Peptides in Soy Sauce. Part II. (see reference 1). This report was presented at the Annual Meeting of the Agricultural Chemical Society of Japan, Tokyo, April, 1973.

* Present address; Fujisawa Yakuhin Kôgyô Co. Ltd., Osaka 563. contributions to the flavor construction in soy sauce were evaluated.

\section{MATERIALS AND METHODS}

The same soy sauce sample as was used in the perceding work ${ }^{13}$ was used in the present work.

Methods of fractionation and analysis were essentially the same as those employed in the preceding work. ${ }^{11}$

The synthetic acidic dipeptides in Table I were synthesized by common methods. All of the synthetic peptides showed a glutamate-like taste at neutral $\mathrm{pH}$, though Kirimura et al. ${ }^{21}$ classified them into the group of sour peptides. However, their taste intensities were all less than $12 \%$ of that of glutamate. ${ }^{31}$

\section{RESULTS}

\section{Preliminary fractionation of acidic substances in} soy sauce on the basis of acidity

As described in the preceding paper $^{1 /}$ five $10 \mathrm{ml}$ aliquots of the soy sauce sample were fractionated by gel filtration on a Sephadex G-15 column, and the fractions from each chromatography were separately subjected to ion exchange chromatography on a QAESephadex A-25 column in the acetate form. After washing out the basic and neutral substances with $0.05 \mathrm{M}$ aqueous acetic acid, the remaining substances on the column were eluted with $0.2 \mathrm{M}$ and $2.0 \mathrm{M}$ aqueous acetic acid and $1.0 \mathrm{~N}$ aqueous hydrochloric acid, sequentially. A $0.1 \mathrm{ml}$ portion of each $7.5 \mathrm{ml}$ fraction 


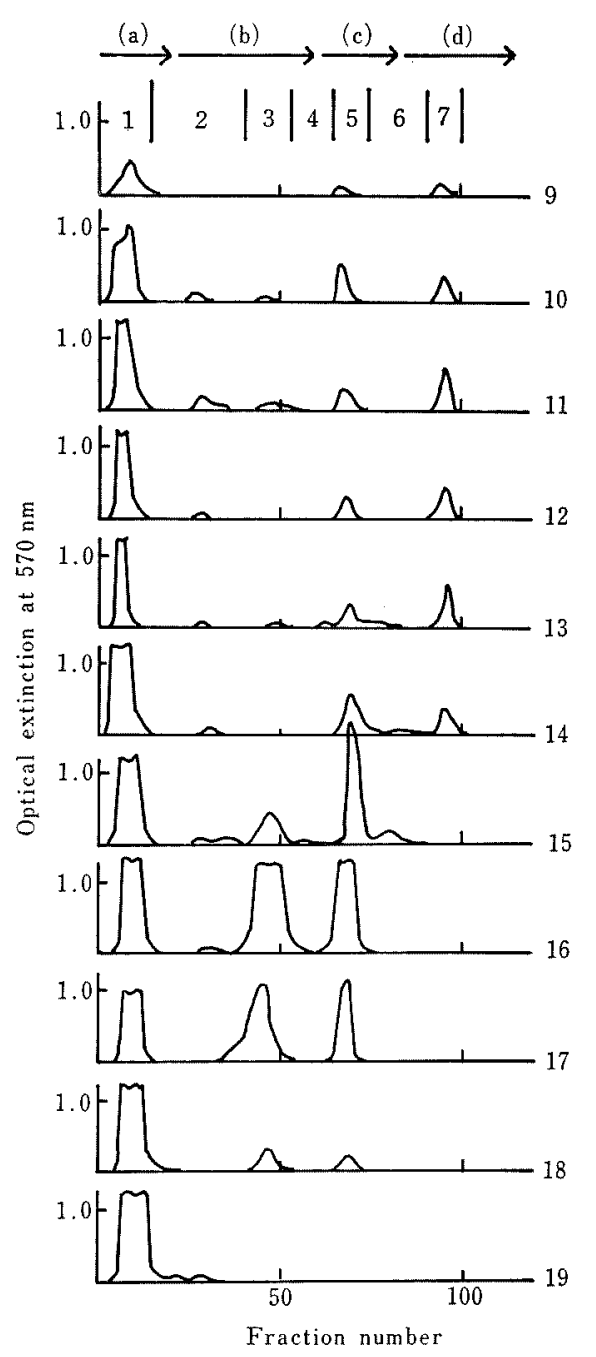

FIG. 1. Fractionation of Acidic Substances in Gel Filtration Fractions on the Basis of Acidity by Stepwise Elution from a QAE-Sephadex Column.

Every fraction from gel filtration on a Sephadex G-15 column of $50 \mathrm{ml}$ of the soy sauce sample was chromatographed on a column of QAE-Sephadex A-25 in acetate form $(2.5 \times 17 \mathrm{~cm})$, and $0.1 \mathrm{ml}$ of eluate from each fraction $(7.5 \mathrm{ml})$ was mixed with $1.0 \mathrm{ml}$ of ninhydrin reagent for the amino acid analyzer and $2.0 \mathrm{ml}$ of the buffer $\left(\mathrm{pH} \mathrm{5.28)}\right.$ and reacted at $100^{\circ} \mathrm{C}$ for $10 \mathrm{~min}$ to monitor the elution process. The optical extinctions at $570 \mathrm{~nm}$ with a $10 \mathrm{~mm}$ light path were plotted versus the fraction number.

The numbers on the right-hand side of the figure represent the fraction numbers in gel filtration.

Elution solvents: (a), 0.05 $\mathrm{M}$ acetic acid; (b), $0.2 \mathrm{M}$ acetic acid; (c), $2.0 \mathrm{M}$ acetic acid; (d), $1.0 \mathrm{~N}$ hydrochloric acid.

Acidity of subfractions: 1 , basic and neutral (B \& N); 2 , weakly acidic (WA); 3 , essentially the same acidity as glutamic acid (GLU); 4, between glutamic acid and aspartic one (AC-1); 5, essentially the same acidity as aspartic acid (ÁSP); 6, more acidic than aspartic acid ( $\mathrm{AC}-2) ; 7$, strongly acidic (SA). was tested with ninhydrin to monitor the elution process. Then, the fractions were pooled to make five groups as illustrated in Fig. 1. The first group is the subfraction containing basic and neutral components, the second is that containing weakly acidic components (WA), the third is that containing the components with essentially the same acidity as glutamic acid (GLU), the fourth is that containing components with acidity between those of glutamic acid and aspartic acid (AC-1), the fifth is that containing components whose acidity is essentially the same as that of aspartic acid (ASP), the sixth is that containing components more acidic than ASP (AC-2) and the seventh is that containing strongly acidic components (SA).

\section{Distribution of peptides in the acidic sub- fractions}

The distribution of ninhydrin-positive substances in the subfractions was examined using the amino acid analyzer. The results are illustrated in Figs. 2-6.

With WA, two major peaks were observed around the elution times for valine and methionine, as shown in Fig. 2. The components of minor peaks in front of the major ones were identified as free amino acids, i.e., threonine, serine, glutamic acid, glycine and alanine, respectively, from their behavior on acid hydrolysis, and thus they are considered to be contaminants. Accordingly, the two major peaks are characteristic of WA. The WA from fractions No. 15 and 16 in gel filtration (15WA and 16-WA) are richest in such peptide substances.

With GLU, glutamic acid was the only component and other peaks were hardly observed, as shown in Fig. 3. With $\mathrm{AC}-1$, as shown in Fig. 4, glutamic and aspartic acids were the major components; the other peaks were very low.

However, in the subfractions of ASP, appreciable amounts of ninhydrin-positive substances were detected in front of the position of aspartic acid, as shown in Fig. 5. With AC-2, larger peaks were observed in the same 


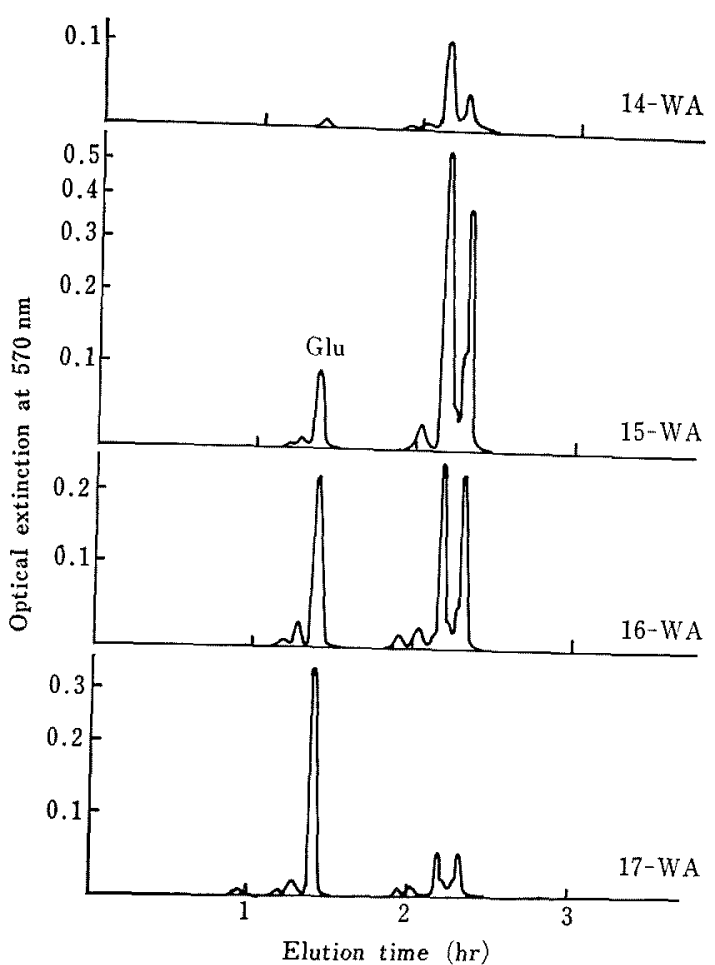

FIG. 2. Distribution of Peptide Substances in WA Subfractions.

Each sample subjected to analysis corresponds to 0.5 $\mathrm{ml}$ of the soy sauce sample.

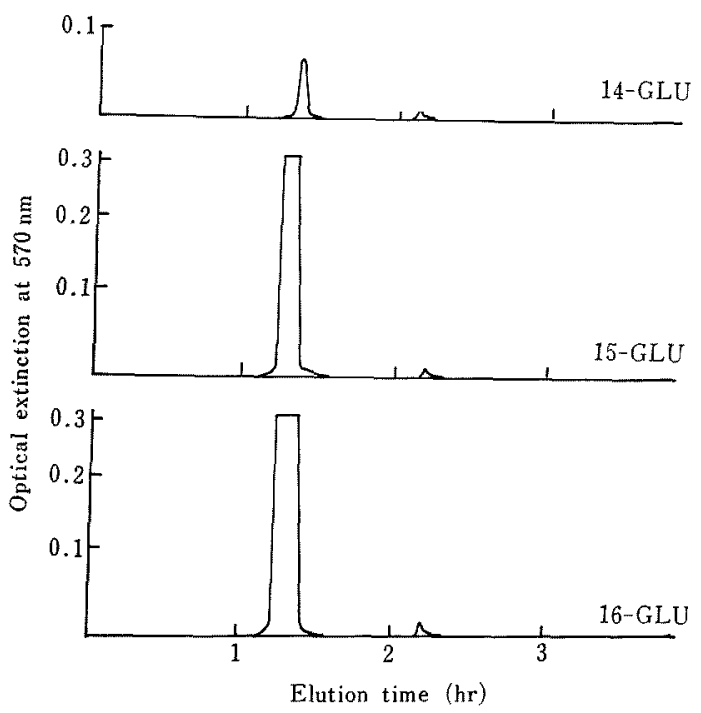

FIG. 3. Distribution of Peptide Substances in GLU Subfractions.

Each sample subjected to analysis corresponds to $0.5 \mathrm{ml}$ of the soy sauce sample.

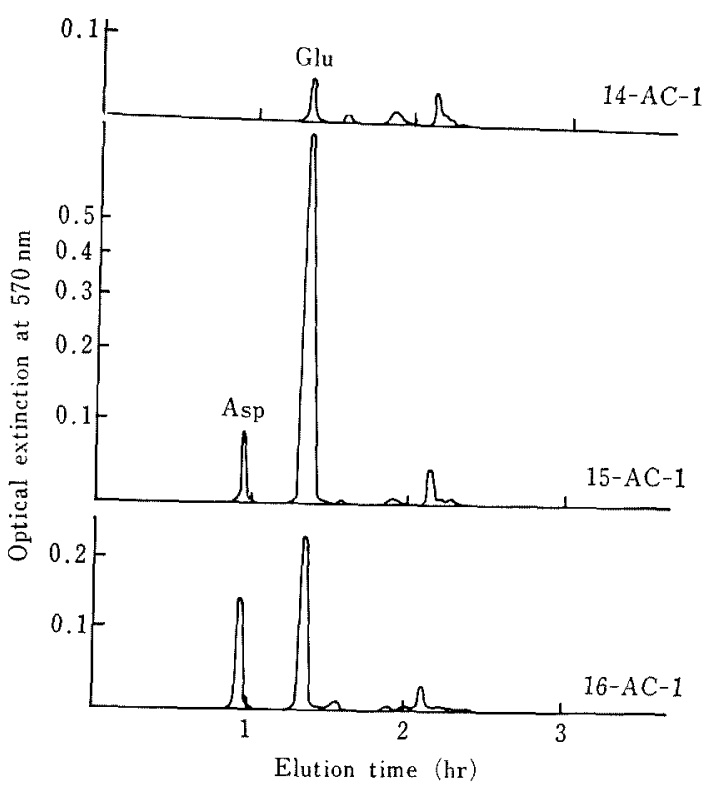

FIG. 4. Distribution of Peptide Substances in AC-1 Subfractions.

Each sample subjected to analysis corresponds to $0.5 \mathrm{ml}$ of the soy sauce sample.

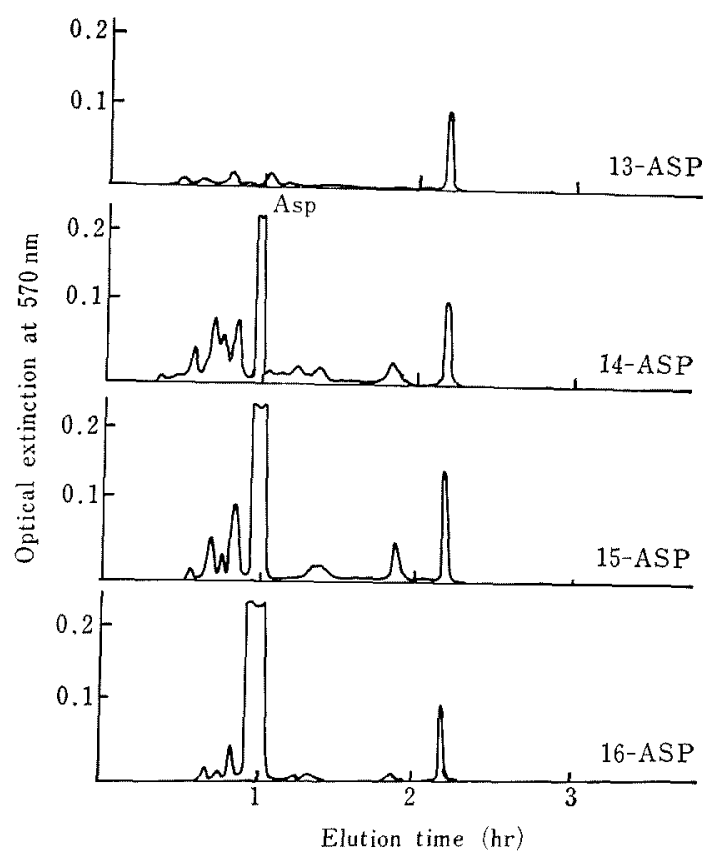

Fig. 5. Distribution of Peptide Substances in ASP Subfractions.

Each sample subjected to analysis corresponds to $0.5 \mathrm{ml}$ of the soy sauce sample. 

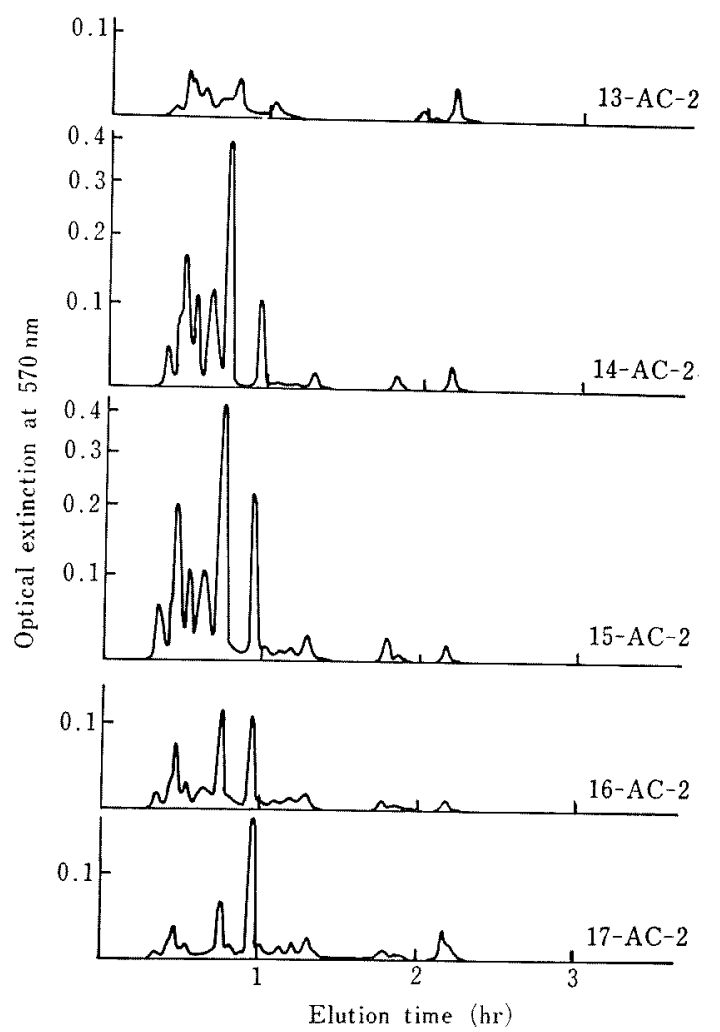

FIG. 6. Distribution of Peptide Substances in AC-2 Subfractions.

Each sample subjected to analysis corresponds to $0.5 \mathrm{ml}$ of the soy sauce sample.

region as for ASP, but the substances in $\mathrm{AC}-2$ are considered to be more acidic than those in ASP on the basis of their behavior in preliminary subfractionation on a QAE-Sephadex column. The substances characteristic of $\mathrm{AC}-2$ are mainly found in fractions No. 14 and 15 on gel filtration.

On the other hand, the substances in SA are mainly found in fraction No. 11 on gel filtration, as shown in Fig. 1, and these substances are considered to have larger molecular size than those mentioned above. The following study is limited to the substances in WA, ASP and $\mathrm{AC}-2$, and those in SA will be the subject of a separate study.

Separation of peptide substances from subfractions with different acidity

Among the subfractions with different acidi- ty, 16-WA, 14-ASP, 14-AC-2 and 17-AC-2 were subjected to further fractionation on the preparative amino acid analyzer, since these fractions seemed to be richest in the characteristic components. Eight fractions corresponding to the peaks detected in the monitoring chromatograms were obtained, as shown in Fig. 7. The peak fractions were desalted on a SE-Sephadex column ${ }^{11}$ and subjected to further separation by paper chromatography.

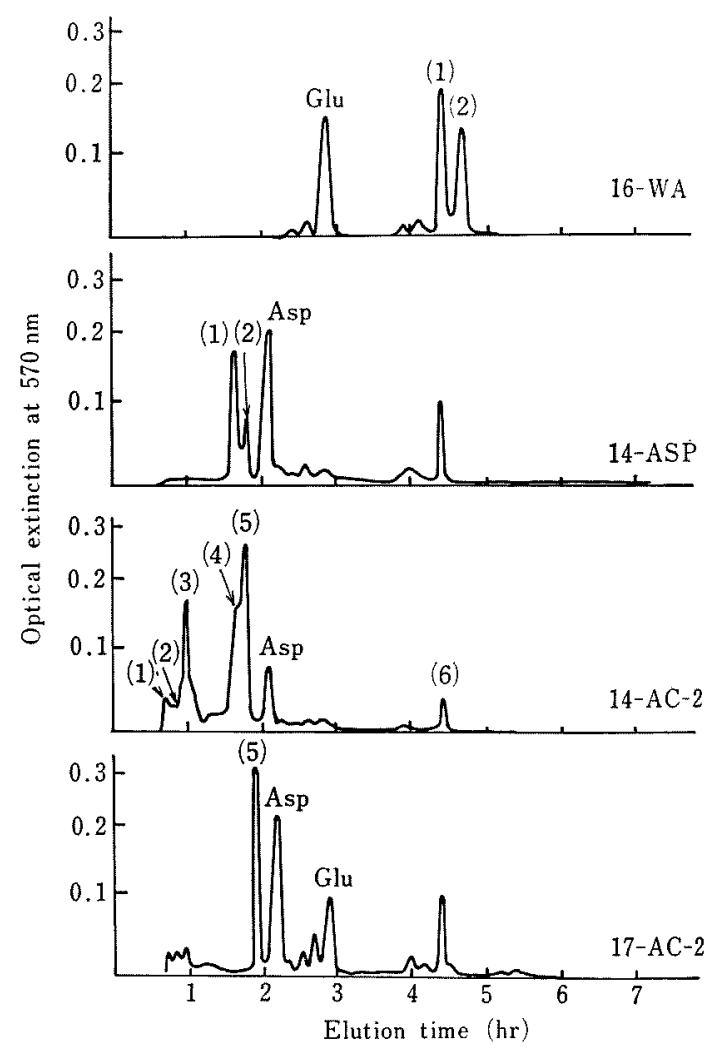

FIG. 7. Preparative Fractionation of Subfractions Using the Amino Acid Analyzer with a Preparative Assembly.

Each sample subjected to fractionation corresponds to about $20 \mathrm{ml}$ of the soy sauce sample.

As shown in Fig. 8, on paper electrophoresis six fractions gave two spots in the cathodic region, but fraction $14-\mathrm{AC}-2-(5)$ gave only one spot. In the case of $14-\mathrm{AC}-2-(3)$, however, no spot was detected. Essentially the same results were obtained by paper chromatography, as shown in Fig. 9. Then, the fractions were 
Table I. Analytical Data for Amino Terminal Amino Acids of Isolated Peptides

\begin{tabular}{|c|c|c|c|c|c|c|}
\hline \multirow{2}{*}{ Fraction } & \multirow{2}{*}{$\begin{array}{l}\text { Amino } \\
\text { acid }\end{array}$} & \multicolumn{2}{|c|}{$\begin{array}{c}\text { Content of residue } \\
\text { (nmole) }\end{array}$} & \multirow{2}{*}{$\begin{array}{l}\text { Assumed } \\
\text { structure }\end{array}$} & \multicolumn{2}{|c|}{ Elution time (hr: $\min )$} \\
\hline & & N-term ${ }^{a 1}$ & residual $^{b}$ & & observed & $\begin{array}{l}\text { synthetic } \\
\text { peptide }^{01}\end{array}$ \\
\hline \multirow[t]{2}{*}{ 16-WA-(1)-a } & Asp & 10 & 112 & Gly-Asp & $2: 13$ & $2: 13$ \\
\hline & Gly & 86 & 15 & & & \\
\hline \multirow[t]{2}{*}{$16-W A-(1)-b$} & Asp & 1 & 10 & Ala-Asp & $2: 12$ & $2: 12$ \\
\hline & Ala & 10 & 2 & & & \\
\hline \multirow[t]{2}{*}{$16-W A-(2)-a$} & Glu & 20 & 144 & Gly-Glu & $2: 18$ & $2: 18$ \\
\hline & Gly & 147 & 25 & & & \\
\hline \multirow[t]{2}{*}{$16-W A-(2)-b$} & Glu & 7 & 24 & Ala-Glu & $2: 18$ & $2: 18$ \\
\hline & Ala & 17 & 4 & & & \\
\hline \multirow[t]{4}{*}{ 14-ASP-(1)-a } & Asp & 48 & 20 & Asp-(Thr/Ser) & $0: 43$ & - \\
\hline & Thr & 0 & 46 & Glu-(Thr/Ser) & $0: 43$ & - \\
\hline & Ser & 0 & 52 & & & \\
\hline & Glu & 42 & 12 & & & \\
\hline \multirow[t]{2}{*}{ 14-ASP-(1)-b } & Thr & 0 & 40 & Glu-Thr & $0: 43$ & - \\
\hline & Glu & 34 & 10 & & & \\
\hline \multirow[t]{4}{*}{$14-A S P-(2)-a$} & Asp & 23 & 5 & Asp-Ala & $0: 53$ & $1: 23$ \\
\hline & Gly & 0 & 17 & Glu-Gly & $0: 53$ & $2: 14$ \\
\hline & Ala & 0 & 26 & & & \\
\hline & Glu & 12 & 3 & & & \\
\hline \multirow[t]{2}{*}{ 14-ASP-(2)-b } & Glu & 7 & 2 & Glu-Ala & $0: 53$ & $2: 18$ \\
\hline & Ala & 0 & 9 & & & \\
\hline $14-\mathrm{AC}-2-(4)-\mathrm{a}^{d !}$ & Asp & 60 & 72 & Asp-Asp & $0: 40$ & $1: 29$ \\
\hline \multirow[t]{2}{*}{$14-\mathrm{AC}-2-(4)-\mathrm{b}^{d \prime}$} & Asp & 5 & 21 & Glu-(Asp, Glu) & $0: 40$ & - \\
\hline & Glu & 12 & 17 & & & \\
\hline \multirow[t]{2}{*}{$14-\mathrm{AC}-2-(5)^{d}$} & Asp & 52 & 52 & Glu-Glu-Glue & $0: 45$ & 一 \\
\hline & Glu & 144 & 274 & & & \\
\hline \multirow[t]{2}{*}{$17-\mathrm{AC}-2-(5)-\mathrm{a}^{d t}$} & Asp & 40 & 8 & Asp-Glu & $0: 45$ & $1: 58$ \\
\hline & Glu & 4 & 52 & & & \\
\hline $\left.17-\mathrm{AC}-2-(5)-\mathrm{b}^{d}\right)$ & Glu & 70 & 68 & Glu-Glu & $0: 45$ & $2: 18$ \\
\hline
\end{tabular}

Each sample subjected to analysis corresponds to about $3.4 \mathrm{ml}$ of the soy sauce sample.

a) Amount of amino acid subtracted by dinitrophenylation.

b) Amount of amino acid remaining after dinitrophenylation.

c) The elution times are consistent with the rule reported by Haworth. ${ }^{4}$

d) A part of the residues may be Asn or Gln; no discrimination from Asp or Glu was carried out.

e) Glu-(Asp,Glu), Asp-(Glu,Glu) and Asp-(Asp,Glu) may also be present as minor components.

subjected to paper chromatography on a preparative scale. The substances in the spots were extracted with deionized water, dried in vacuo and subjected to the following analyses.

\section{Characterization of isolated acidic peptides}

Analysis of the amino-terminal amino acids of the isolated substances was carried out by the subtraction method in the same manner as in the preceding paper. ${ }^{1)}$

The analytical data are summarized in Table I. The results indicate that the isolated peptide substances are all dipeptides, except those in $14-\mathrm{AC}-2-(4)-\mathrm{b}$ and $14-\mathrm{AC}-2-(5)$ which are assumed to be tripeptides. It is of interest that every substance in WA is composed of a neutral amino acid at the amino terminal and an acidic one at the carboxyl terminal, and every substance in ASP is constructed in the opposite sequence. The substances in AC-2 are composed of only acidic amino acids.

On the other hand, the elution times of the substances isolated from WA coincide well with those of the corresponding synthetic dipeptides. However, the substances isolated from ASP and $\mathrm{AC}-2$ are eluted in front of aspartic acid 


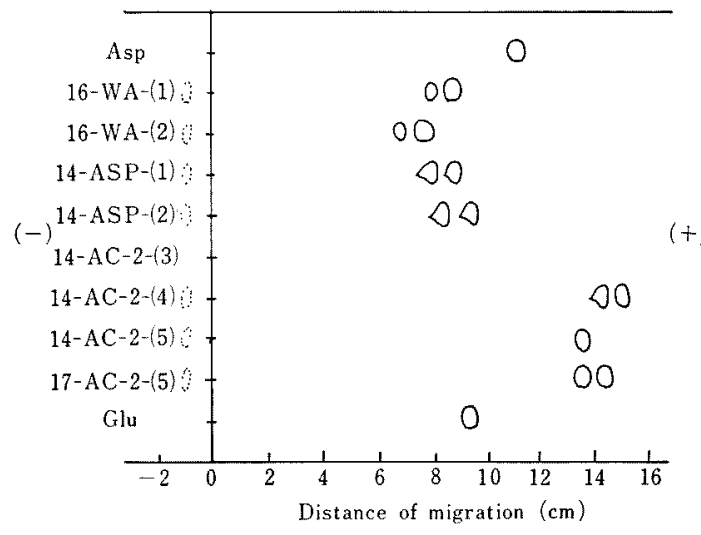

FIG, 8. Paper Electrophoretic Behavior of Substances Separated on the Preparative Amino Acid Analyzer.

Conditions of electrophoresis: $75 \mathrm{~V} / \mathrm{cm}, 30 \mathrm{~min}$ at $5^{\circ} \mathrm{C}, 0.05 \mathrm{~m}$ sodium acetate buffer ( $\mathrm{pH} 5.5$ ). Spots were detected by ninhydrin reaction.

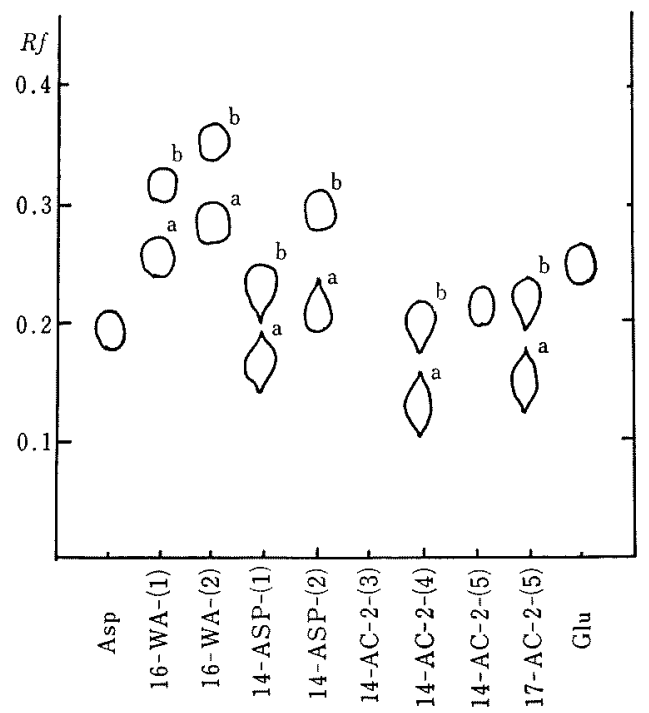

Fig. 9. Paper Chromatogram of Substances Separated on the Preparative Amino Acid Analyzer.

Solvent system was $n$-butanol/acetic acid/water (3: 1 : 1) $(v / v)$.

Spots were detected by ninhydrin reaction.

$(0: 57)$ by the amino acid analyzer, while the corresponding synthetic peptides are eluted with longer elution times, as shown in Table I, though the available peptides were limited. This situation is apparently similar to that observed in the preceding work. ${ }^{1 \prime}$ Thus, they are considered to be not simple peptides, but conjugated ones.
Detection of sugar substances in isolated acidic peptide substances

As shown in Table II, the sugar contents

Table II. Sugar Contents in Isolated Peptides

\begin{tabular}{lccc}
\hline Component & $\begin{array}{c}\text { Peptide } \\
\text { moiety }^{a} \text { (nmole) } \\
\text { (nmole }\end{array}$ & $\begin{array}{c}\text { Content } \\
\text { of sugar }^{b)} \\
\text { glucose) }\end{array}$ & $\begin{array}{c}\text { Mole ratio } \\
\text { of sugar to } \\
\text { peptide }\end{array}$ \\
\hline 16-WA-(1)-a & 35 & 9 & 0.25 \\
16-WA-(2)-a & 52 & 11 & 0.21 \\
14-ASP-(1)-a & 50 & 55 & 1.10 \\
14-ASP-(1)-b & 22 & 55 & 2.50 \\
14-ASP-(2)-a & 40 & 60 & 1.50 \\
14-ASP-(2)-b & 20 & 60 & 3.00 \\
14-AC-2-(4)-a & 40 & 45 & 1.12 \\
14-AC-2-(4)-b & 25 & 45 & 1.8 \\
17-AC-2-(5)-a & 45 & 50 & 1.1 \\
17-AC-2-(5)-b & 45 & 50 & 1.1 \\
\hline
\end{tabular}

a) The content of peptide moiety was calculated from the amount of the N-termial amino acid shown in Table I.

b) The sugar content was determined by the phenolsulfuric acid method. ${ }^{1 !}$

were as high as one or two equivalents per mole of the corresponding peptide moiety in the cases of the substances from ASP and AC-2, while the contents are less than 0.25 equivalent per mole in the cases of substances from WA. Thus, it is considered that the substances from ASP and AC-2 are sugar derivatives.

The peptide substances were chromatographed on paper before and after the partial hydrolysis treatment and spots with reducing power were inspected. One reducing spot was detected after treatment, while no spots were detected before the treatment. The $R f$ values were essentially the same and correspond to those of arabinose and some other hexoses, as shown in Fig. 10.

From these facts, it is considered that the peptide substances in ASP and AC-2 are all sugar derivatives.

\section{DISCUSSION}

In the present work, four simple dipeptides 
Table III. Estimation of the Contents of Acidic Peptides in the Soy Sauce Sample ( $\mu$ mole/ml)

The values in this table were estimated from the peak areas in Fige. $2 \sim 6$ under the assumption that the coefficients for calculating the mole contents of these substances are essentially the same as that for glutamic acid.

\begin{tabular}{lcccccc}
\hline & \multicolumn{7}{c}{ Fraction number in gel filtration } & & Total \\
\cline { 2 - 6 } Subfraction & 13 & 14 & 15 & 16 & 17 & 1.22 \\
\hline WA-(1) & - & 0.18 & 0.68 & 0.26 & 0.10 & 1.00 \\
WA-(2) & - & 0.10 & 0.48 & 0.32 & 0.10 & 0.80 \\
ASP-(1) & 0.04 & 0.36 & 0.34 & 0.06 & - & 0.72 \\
ASP-(2) & 0.02 & 0.24 & 0.36 & 0.10 & - & 0.40 \\
AC-2-(4) & 0.04 & 0.20 & 0.10 & 0.06 & - & 0.82 \\
AC-2-(5) & 0.04 & 0.30 & 0.36 & 0.08 & 0.04 & 0.24 \\
Total & 0.14 & 1.38 & 2.32 & 0.88 & 0.96 \\
\hline
\end{tabular}

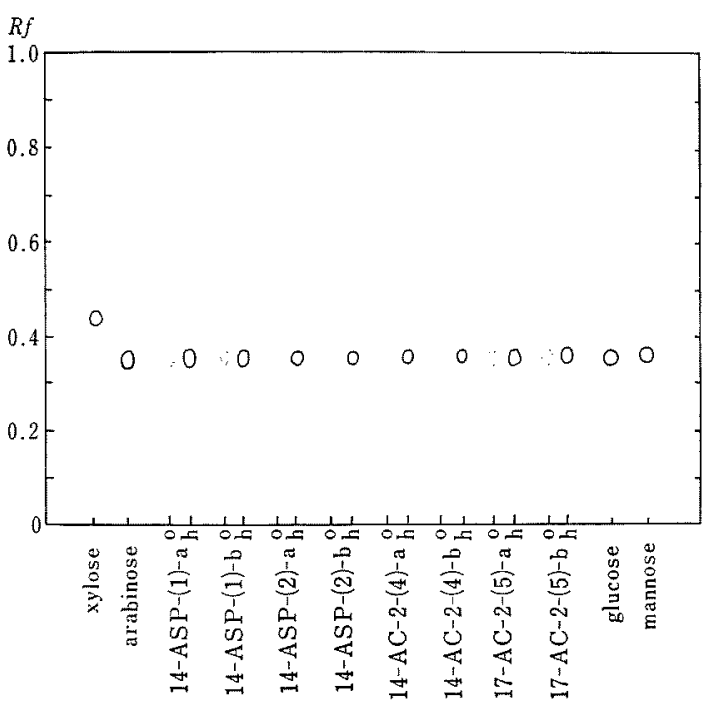

FIG. 10. Paper Chromatogram of Isolated Peptides before and after Partial Hydrolysis for the Detection of Reducing Sugars.

Reducing spots were detected with alkaline silver nitrate. ${ }^{5)}$ Solvent system was $n$-butanol/pyridine/ water $(6: 4: 3)(\mathrm{v} / \mathrm{v})$.

and eleven conjugated dipeptides were isolated from a soy sauce sample as the major acidic peptide substances, and their amino acid sequences were determined. In addition, the presence of several acidic tripeptides was shown.

These substances are classified into three groups, WA, ASP and AC-2, on the basis of acidity as estimated from the behavior in QAESephadex chromatography.

The substances in WA are simple dipeptides composed of a neutral amino acid at the amino terminal and an acidic one at the-carboxyl terminal; they were identical with the corresponding synthetic peptides in chromatographic behavior on the amino acid analyzer. However, the substances in $\mathrm{ASP}$ and $\mathrm{AC}-2$ were characterized as conjugated peptides having a sugar moiety; their elution times on the amino acid analyzer were very much shorter than those expected from the corresponding synthetic simple peptides, though the number of available synthetic compounds was limited, as shown in Table I.

Since the substances in 14-ASP-(1) contain one mole of $\beta$-hydroxy amino acid, they can bind the sugar moiety as an $O$-glycoside. The substances in 14-AC-2 and 17-AC-2 are composed of two or three moles of acidic amino acids, and thus they can bind the sugar moiety as an $\mathrm{N}$-glycoside, assuming that one of the residues is in the form of glutamine or asparagine. However, the substances in 14-ASP-(2) cannot be $O$ - or $\mathrm{N}$-glycoside, because they have no hydroxyl group and only one acidic amino acid. The identification of the sugar moiety and the analysis of these linkages between peptide and sugar are still objects of study. The contents of these substances in the soy sauce sample can be roughly estimated from the peak areas in Fig. 2, as shown in Table III.

The total amount of simple dipeptides in WA is estimated to be $2.2 \mu$ mole per $\mathrm{ml}$ of the soy sauce sample. As found in other 
work, ${ }^{3}$ ) the taste intensities of the corresponding synthetic peptides are less than $12 \%$ of that of glutamate, though they show a glutamate-like taste in organoleptic examination in a neutral medium. Thus, the dipeptides in WA are considered to correspond in taste to glutamate of less than $0.26 \mu \mathrm{mole} / \mathrm{ml}$. This value is lower than the threshold concentration of glutamate, $0.8 \mu \mathrm{mole} / \mathrm{ml}$. Accordingly, no direct contribution of these substances to flavor construction can be expected.

The total amount of conjugated peptides in ASP and AC-2 is estimated to be $2.7 \mu \mathrm{mole} / \mathrm{ml}$ from Table III. Although synthetic compounds corresponding to these substances are not available and evaluation of their taste intensities is impossible at present, it can be considered that the taste intensity of these substances in total does not greatly exceed that of glutamate at its threshold concentration. Accordingly, the contribution of the above acidic peptide substances to the flavor construction, if any, is expected to be as a potentiator rather than as directly contributing components.

The amount of potential amino acids in the acidic and strongly acidic fractions of the soy sauce were estimated to be more than 130 $\mu \mathrm{mole} / \mathrm{ml}$ in total in the preceding work. ${ }^{11}$ The residual amounts of amino acid derivatives other than those characterized in the present work are large enough to leave the role of the latter substances obscure. The former substances must be in forms negative to ninhydrin. Accordingly, substances negative to ninhydrin reaction may be important in the flavor problem. Studies on these substances are being continued in the author's laboratory.

\section{REFERENCES}

1) S. Oka and K. Nagata, Agr. Biol. Chem., 38, 1185 (1974).

2) J. Kirimura, A. Shimizu, A. Kimizuka, T. Ninomiya and N. Katsuya, J. Agr. Food Chem., 17, 689 (1969).

3) S. Oka, H. Okai and S. Ohyama, Abstracts of papers, Annual Meeting of the Agricultural Chemical Society of Japan, Tokyo, April, 1973, p. 99.

4) C. Haworth, J. Chromatog., 67, 315 (1972).

5) W. E. Trevelyan, D. P. Procter and J. S. Harrison, Nature, 166, 444 (1950). 